\title{
Tuberculosis risk factors in Lephalale local municipality of Limpopo province, South Africa
}

\author{
T.M. Ramaliba ${ }^{a b}$, T.G. Tshitangano ${ }^{a}$, H.A. Akinsola ${ }^{a}$ and M. Thendele ${ }^{a *}$ iD \\ ${ }^{a}$ Department of Public Health, School of Health Sciences, University of Venda, Thohoyandou, South Africa \\ ${ }^{\circ}$ HAST Research Programme, Human Sciences Research Council, Pretoria, South Africa \\ *Corresponding author, email: mervisthendele@gmail.com
}

Lephalale local municipality is the leading sub-district in Limpopo province with $9.8 \%$ of deaths caused by tuberculosis. This study aimed to describe the risk factors for TB in Lephalale local municipality. A quantitative descriptive, cross-sectional survey design was used to target 148 registered TB patients aged 18 years and above in the sub-district's 6 clinics. Approval and ethical clearance was obtained from the relevant authorities (SHS/15/PH/14/2006). Only respondents who agreed in writing to be part of the study were included. Ethical research principles were observed. A researcher-developed self-administered questionnaire was used to collect data. The data were analysed using the Statistical Package for Social Sciences ${ }^{\circledast}$ version 22.0. Of 148 respondents, a high proportion of diagnosed TB patients (43.24\%) were receiving less than R1 000 per month; the majority $(53.38 \%)$ were unemployed; $22 \%$ were overcrowded in a single room; $31.8 \%$ had skipped taking TB medication at some point; $12 \%$ had previously worked in the mining industries; $37.16 \%$ never opened windows: $39.19 \%$ were from a rural settlement. TB risk factors in Lephalale include overcrowding, inadequate ventilation, TB treatment interruption, rural settlement, working in a mine, and low income. Educating communities about improving ventilation and treatment adherence as well as community empowerment with entrepreneurial skills might assist.

Keywords: cultural, risk, socio-economic, tuberculosis

\begin{abstract}
Introduction
Tuberculosis is one of the critical global health issues currently. ${ }^{1}$ The World Health Organization ${ }^{2}$ estimated that there were 9 million incident cases of TB and 1.1 million deaths among nonHIV cases of TB in 2015 worldwide. According to Siddiqui et al., ${ }^{3}$ every two minutes 36 people are infected with TB, and among these six die. At present one-third of the earth's population is infected with TB. ${ }^{2}$ In 2010, Africa alone contributed $26 \%$ of the global burden with 9 of the 22 high-burden countries contributing $81 \%$. Tuberculosis causes great illness in povertyaffected populations, especially in low-income countries, with Kenya ranking 15th among the 22 burden countries in the world and 5th in Africa. The country had 74335 new cases. ${ }^{2}$
\end{abstract}

South Africa had the third highest burden of disease in the world, after India and China, with an estimated incidence of 450000 cases of active TB in 2013, an increase of $400 \%$ over the last 15 years. ${ }^{1}$ An estimated $60-73 \%$ of the 450000 incident cases have both HIV and TB infection. The incidence of multi-drug resistant (MDR) and extensively drug-resistant TB are increasing. ${ }^{4}$ South Africa has the second highest number of reported multidrug resistant TB (MDR-TB) cases globally. ${ }^{5}$ TB remains the leading cause of death in South Africa. ${ }^{6}$ Limpopo province had 17301 national TB cases and ranked number seven among all nine provinces. Tuberculosis is one of the major problems in Limpopo province and it is regarded as the first priority of the Department of Health strategy plan. ${ }^{7}$ According to Tshitangano, ${ }^{8}$ Limpopo province has gradually recorded an increase in TB load, up from 11897 in 2005 to 22158 in 2011.

Motsoaledi ${ }^{9}$ emphasised that South Africa is facing challenges in terms of controlling TB in the mines with about 41810 cases of active TB detected every year. According to Motsoaledi, ${ }^{9}$ the incidence of TB in the mining industry is higher than in any other working population in the world, and 9.6 million work days are lost each year to TB. The mining industry acts as a conduit to increase the spread of TB in communities around the mines. In 2012, Waterberg district was the leading district in Limpopo province with $9.8 \%$ of deaths caused by TB. ${ }^{7}$ Lephalale local municipality remains the area of research interest as it forms part of Waterberg district. According to Taha et al., ${ }^{10}$ the determinants of active TB in HIV/AIDS patients include factors such as socioeconomic status, which include ownership of house, income, residence, marital status, occupation and education; there are also proximate determinants, which include age, sex, and previous history of TB. One common and useful way to contribute to the control of tuberculosis is to identify the important risk factors for tuberculosis. Studies have addressed the issue of behaviour and biomedical aspects as the risk factors associated with tuberculosis. ${ }^{11}$ A study conducted by Padmapriyadarsini et al. ${ }^{12}$ found that HIV is associated with tuberculosis. Diabetes mellitus is another disease associated with tuberculosis. ${ }^{13}$ According to Odone et al., ${ }^{13}$ malnutrition has been seen to be a risk factor associated with tuberculosis. The $\mathrm{WHO}^{1,2}$ asserts that identifying and managing the risk factors (determinants) is one useful strategy to control TB. This study therefore aimed to describe the risk factors for TB in Lephalale local municipality, South Africa. The following objectives directed the study:

(1) to explain demographic and socio-economic factors that contribute to the spread of TB in Lephalale local municipality;

(2) to describe cultural factors that contribute to the spread of TB in Lephalale local municipality; 
(3) to describe environmental factors that contribute to the spread of TB in Lephalale local municipality;

(4) to assess attitudes and behaviour associated with the spread of TB in Lephalale local municipality.

\section{Methods}

A cross-sectional survey was found to be the most suitable design to address the objectives of this study. The research method used was quantitative descriptive in nature. The study was conducted at Lephalale local municipality where 148 registered TB patients aged 18 years and above in 6 clinics using a TB register were included in the study population. The participants had to be registered in any of the six clinics. Only respondents who agreed in writing to be part of the study were included.

\section{Sampling}

The sample size for this study was calculated using Slovin's formula, where $\mathrm{N}$ was the total number of TB patients, $\mathrm{n}$ was the sample size and e was the accepted level of error. The accepted level of error, e, was 0.05 . Therefore the sample size was 149 as calculated below:

$$
\begin{aligned}
& \frac{n=N}{1+N\left(e^{2}\right)} \\
& \frac{n=238}{1+238(0.05)^{2}} \\
& \frac{n=238}{1+0.5925} \\
& \frac{n=238}{1.5925} \\
& \frac{n=148.2}{n=148}
\end{aligned}
$$

To select the participants from the target population until the sample was reached, two sampling methods were utilised. First the stratified random sampling technique was employed by dividing groups (strata) according to their clinics then systematic random sampling was used to select names from the clinics' TB registers. The total number of TB registered patients was divided by the sample size to find the $\mathrm{K}$ value, which is the interval value; $\mathrm{K}$ value $=238 / 148=2$. Therefore, every second TB patient from the register was selected to participate in the study until the sample size of 148 was reached.

\section{Data collection}

Data were collected using a self-administered questionnaire, which consisted of open and closed ended questions. A researcher developed self-administered questionnaire was used to collect the data: Section A: Socio-demographic characteristics that include age, employment status, sex, income, type of income and level of education; Section B: Environment factors; Section C: Personal Risk factors; and Section D: Attitude and behaviours. Prior to the collection of data, approval and ethical clearance were obtained from the University of Venda SHS/15/ $\mathrm{PH} / 14 / 2006)$ and the provincial Department of Health, Limpopo Province. Principles of self-determination, anonymity, confidentiality, informed consent and protection from harm were observed throughout the data-collection process. Data were collected in clinics by the researcher, assisted by clinic managers. Moreover, the dates were arranged with the nurses to confirm the availability of TB patients. Questionnaires were administered to the participants when they came for their monthly TB treatment schedule. Eligible participants were requested to sign the consent form once they agreed to participate in the study.

\section{Reliability and validity of questionnaire instrument}

The questionnaire was presented to staff members from the Department of Public Health at the University of Venda and also presented to the members of the Higher Degree Committee (HDC) of the School of Health Sciences in order to assess its appropriateness and assist where anything was lacking. Content validity was also observed throughout the evaluation by environmental health specialists, supervisors, lecturers from the department and other departments, together with students who attended the departmental seminars. To ensure validity of the questionnaire an extensive literature search was conducted and the research developed in line with the objectives. Furthermore the questionnaire was developed in close cooperation with TB experts who evaluated it before data collection, hence its validity. Instrument reliability was ensured by the test-retest method. The researcher administered the questionnaire to 10 participants in Lephalale hospital. After two weeks the researcher administered the instrument to the same 10 participants for a second time. The scores for test and retest were compared and there was a small difference. Cronbach's alpha, which measures the degree of internal consistency $(0 \leq \alpha \leq 1.0)$ of the instrument, was used to ascertain the reliability of the instrument. The results yielded an alpha $(\alpha)$ value of 0.84 ; it was therefore concluded that the instrument had high consistency and thus was reliable.

\section{Statistical analysis}

The Statistical Package for Social Sciences ${ }^{\circledR}$ (SPSS) version 22.0 (IBM Corp, Armonk, NY, USA) was used to analyse the data in the form of frequency and percentages. Data analysis was carried out using SPSS version 22.0, whereby the frequency distribution and cross-tabulation were used. Every response item on the questionnaire was carefully entered as a numbered code under the question header in SPSS when all the survey questionnaires had been collected. A data-cleaning process was employed to produce quality data and referring back to the objectives of the study.

\section{Results}

From all selected cases of TB patients, 148 completed questionnaires out of 149 targeted sample giving a $99.3 \%$ response rate. The results were presented according to the objectives outlined in the introduction, namely demographic factors, socio-economic factors, environmental factors and attitudes and behaviour associated with TB.

\section{Demographic factors}

Of 148 respondents, a high proportion of diagnosed TB patients (43.24\%) were receiving less than R1 000 per month; the majority $(53.38 \%)$ were unemployed; $22 \%$ were overcrowded in a single room; $31.8 \%$ had skipped taking TB medication at some point; $12 \%$ had previously worked in the mining industries; $37.16 \%$ never opened windows; $39.19 \%$ were from a rural settlement. The results revealed that $20.95 \%$ were within the $34-40$ years age bracket with a slight difference of $20.27 \%$ falling in the range of $26-33$ years of age. More than half $(52.7 \%)$ of the respondents were males while $43.5 \%$ were females. 
Among the respondents $70 \%$ were unemployed while $33.7 \%$ depended on a government grant. The majority of the respondents (43.24\%) receive an income of less than R1 000 per month. About $54.05 \%$ had secondary education as compared with $12.8 \%$ who did not attend school at all. About $12 \%$ of the respondents indicated that they had previously worked in the mining industries. About $12.1 \%$ of the respondents worked on farms, while the majority of the respondents were unemployed $(53.38 \%)$ and dependent on a grant of less than R1 000 (see Table 1).

\section{Cultural risk factors}

Table 2 indicates that $18.92 \%$ of TB patients first consulted a traditional healer before they went to the health care centre. About $58.11 \%$ of TB respondents visited the health care centre for their first TB consultation. The results show that $18.92 \%$ of respondents had a family history of TB, while $81.08 \%$ had no family history of TB.

\section{Environmental risk factors}

The majority of respondents' houses $(79.05 \%)$ had windows compared with $20.95 \%$ who did not. Few $(31.76 \%)$ respondents were opening windows frequently compared with $37.16 \%$ who never did and $31.8 \%$ who sometimes do so (see Table 3 ).

The participants (Figure 1a) also indicated that (49\%) of respondents had shared a room in the past, while (45\%) had not shared a room in the past year. Some $6 \%$ of the respondents shared a room. Figure $1 \mathrm{~b}$ indicates that $(22 \%)$ of respondents were overcrowded in a single room, and about 30\% of respondents were accommodating two people per single room. Figure $1 \mathrm{c}$ indicates that $12 \%$ of the respondents stated that they had previously worked in the mining industries, while $9.1 \%$ of them worked in health facilities such as clinics and hospitals. About $12.1 \%$ of the respondents had work in farming, while the majority of the respondents were unemployed (53.38\%).

\section{Attitude and behaviour risk factors}

Table 4 indicates that (31.8\%) of respondents had skipped taking medication, while $68.2 \%$ were taking medication every day. The results also show that respondents were ashamed to discover that they had TB (20.27\%). About $77.7 \%$ disagreed with this statement. The table indicates that $51.35 \%$ of respondents were hiding their TB status while $46.62 \%$ had disclosed their TB status to relatives and friends. Some $92 \%$ of TB patients agreed that having TB affects relationships with family members, while $37.84 \%$ of respondents believed that having TB does not affect their relationship with family members. A high proportion of TB patients $(43.92 \%)$ will take their medication despite the side effects as long as they manage to finish the treatment, while $37.84 \%$ believe that drug side effects affect the process of completing treatment.

Cross-tabulation was employed to investigate any association between geographic area and stigmatisation. Rural formal (43.1\%) and urban informal (51.35\%) TB patients were respectively associated with stigma $(p$-value $=0.002)$ (see Table 4).

\section{Discussion}

The discussion is arranged under sub-headings based on the objectives of the study, namely socio-cultural risk factors,
Table 1: Socio-economic and demographic characteristics.

\begin{tabular}{|c|c|c|}
\hline Variables & Frequency $(n=148)$ & $\%$ \\
\hline \multicolumn{3}{|l|}{ Age } \\
\hline $18-25$ & 23 & 15.54 \\
\hline $26-33$ & 30 & 20.27 \\
\hline $34-40$ & 31 & 20.95 \\
\hline $41-47$ & 25 & 16.89 \\
\hline $48-55$ & 11 & 7.43 \\
\hline $56+$ & 28 & 18.92 \\
\hline \multicolumn{3}{|l|}{ Sex } \\
\hline Male & 78 & 52.70 \\
\hline Female & 70 & 47.30 \\
\hline \multicolumn{3}{|l|}{ Marital status } \\
\hline Married & 28 & 18.92 \\
\hline Single & 66 & 44.59 \\
\hline Separated & 39 & 26.35 \\
\hline Cohabiting & 13 & 8.78 \\
\hline Widowed & 2 & 1.35 \\
\hline \multicolumn{3}{|l|}{ Education level } \\
\hline None & 19 & 12.84 \\
\hline Primary & 28 & 18.92 \\
\hline Secondary & 80 & 54.05 \\
\hline Tertiary & 21 & 14.19 \\
\hline \multicolumn{3}{|l|}{ Occupation } \\
\hline Unemployed & 104 & 70.27 \\
\hline Employed & 30 & 20.27 \\
\hline Self-employed & 14 & 9.46 \\
\hline \multicolumn{3}{|l|}{ Type of income } \\
\hline Salary & 27 & 18.24 \\
\hline Grant/pension fund & 50 & 33.78 \\
\hline Profit (business) & 15 & 10.14 \\
\hline Student & 13 & 8.78 \\
\hline None & 43 & 29.05 \\
\hline \multicolumn{3}{|l|}{ Income } \\
\hline less R1 000 & 64 & 43.24 \\
\hline R1 000-R3 000 & 56 & 37.84 \\
\hline R4 000-6000 & 6 & 4.05 \\
\hline R7 000-10000 & 5 & 3.38 \\
\hline$>\mathrm{R} 10000$ & 17 & 11.49 \\
\hline
\end{tabular}

Table 2: First place consulted before being diagnosed with TB and history of TB in the family.

\begin{tabular}{|lcc|}
\hline Variables & $\boldsymbol{n = 1 4 8}$ & $\%$ \\
\hline First place for consultation & 28 & \\
\hline Traditional healer & 6 & 18.92 \\
\hline Pharmacy & 86 & 4.05 \\
\hline Healthcare centre & 22 & 58.11 \\
\hline Hospitals & 5 & 14.86 \\
\hline Self-medication & 1 & 3.38 \\
\hline Prayer/church & & 0.68 \\
\hline Family diagnosed with TB & 28 & \\
\hline Yes & 120 & 18.92 \\
\hline No & & 81.08 \\
\hline
\end{tabular}


Table 3: Environmental factors: indoor ventilation.

\begin{tabular}{lcc}
\hline Variables & $\boldsymbol{n}=\mathbf{1 4 8}$ & $\%$ \\
\hline Does your dwelling have windows? & & \\
\hline Yes & 117 & 79.05 \\
\hline No & 31 & 20.95 \\
\hline Were you opening the window to allow fresh air indoors? & & \\
\hline Yes & 47 & 31.76 \\
\hline No & 55 & 37.16 \\
\hline Sometimes & 46 & 31.08 \\
\hline
\end{tabular}

Were you sharing a room in the past

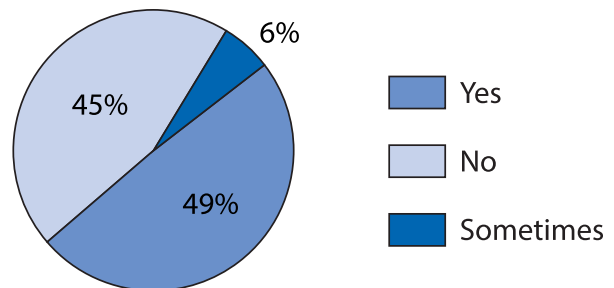

Figure 1a: Living arrangements.

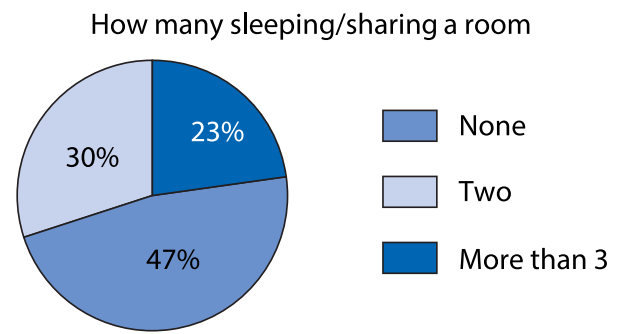

Figure 1b: Overcrowding.

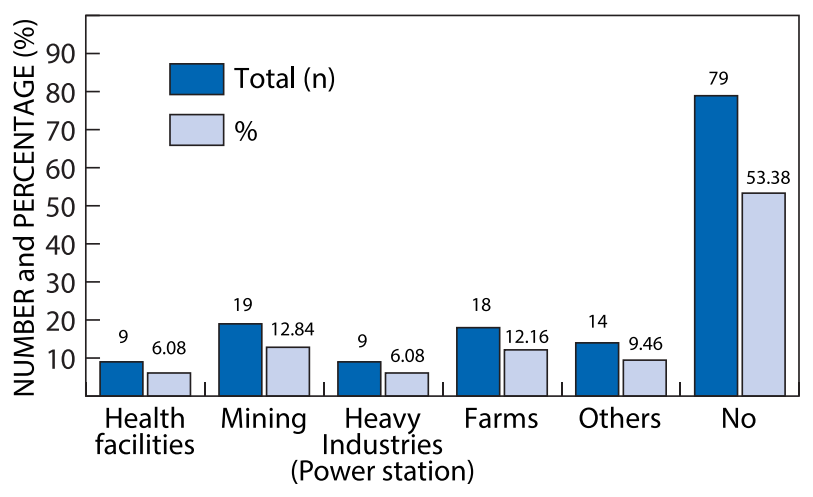

Work place of the respondents in past two years (148)

Figure 1c: Work environment.

environmental risk factors, economic factors, and attitudes and behaviour associated with the spread of TB. In this study people living with TB are in the age brackets $34-40$ years and 2633 years, which is to say that the young economically productive age groups suffer more from tuberculosis. Previous studies have reported a rapid rise in TB mortality and morbidity among this young adult population, mostly between 15 and 44 years of age ${ }^{14}$ which is in line with the findings showing higher HIV infection in these age groups in sub-Saharan Africa.
Table 4: Attitude of the respondents towards TB.

\begin{tabular}{|c|c|c|c|c|}
\hline Variable & \multicolumn{2}{|c|}{$n=148$} & \multicolumn{2}{|c|}{$\%$} \\
\hline \multicolumn{5}{|c|}{ Have you skipped taking medication? } \\
\hline Yes & \multicolumn{2}{|c|}{47} & \multicolumn{2}{|c|}{31.76} \\
\hline No & \multicolumn{2}{|c|}{101} & \multicolumn{2}{|c|}{68.24} \\
\hline \multicolumn{5}{|c|}{ Were you ashamed when you found out that you have TB? } \\
\hline Disagree & \multicolumn{2}{|c|}{115} & \multicolumn{2}{|c|}{77.70} \\
\hline Neutral & \multicolumn{2}{|c|}{3} & \multicolumn{2}{|c|}{2.03} \\
\hline Agree & \multicolumn{2}{|c|}{30} & \multicolumn{2}{|c|}{20.27} \\
\hline \multicolumn{5}{|c|}{ I always hide TB status to avoid being stigmatised } \\
\hline Disagree & \multicolumn{2}{|c|}{69} & \multicolumn{2}{|c|}{46.62} \\
\hline Neutral & \multicolumn{2}{|c|}{3} & \multicolumn{2}{|c|}{2.03} \\
\hline Agree & \multicolumn{2}{|c|}{76} & \multicolumn{2}{|c|}{51.35} \\
\hline \multicolumn{5}{|c|}{ Does having TB affect your relationship with other family members } \\
\hline Disagree & \multicolumn{2}{|c|}{56} & \multicolumn{2}{|c|}{37.84} \\
\hline Neutral & \multicolumn{2}{|c|}{27} & \multicolumn{2}{|c|}{18.24} \\
\hline Agree & \multicolumn{2}{|c|}{65} & \multicolumn{2}{|c|}{43.92} \\
\hline \multicolumn{5}{|c|}{ I will keep taking treatment despite the side effects as long I finish treatment } \\
\hline Disagree & \multicolumn{2}{|c|}{30} & \multicolumn{2}{|c|}{20.27} \\
\hline Neutral & \multicolumn{2}{|c|}{25} & \multicolumn{2}{|c|}{16.89} \\
\hline Agree & \multicolumn{2}{|c|}{93} & 62. & \\
\hline Geographic area settle- & I always hid & e TB status & $\begin{array}{l}\text { avoid bein } \\
\text { d }\end{array}$ & stigma- \\
\hline & Disagree & Neutral & Agree & $p$-value \\
\hline Rural formal & $32(55.17)$ & $1(1.72)$ & $25(43.10)$ & 0.002 \\
\hline Rural informal & $13(65)$ & 0.00 & $7(35)$ & \\
\hline Urban formal & 0.000 & 0.00 & $16(100)$ & \\
\hline Urban informal & $24(44.44)$ & $2(2.03)$ & $76(51.35)$ & \\
\hline
\end{tabular}

With regard to gender and TB morbidity this study showed that a significantly higher percentage of males $(52.70 \%)$ as compared with females (47.30\%) are affected by TB. Evidence from a study conducted by the World Health Organization reports that males are 1.4 times more likely to have TB than females. ${ }^{1}$ These findings were supported by Gomes et al., ${ }^{15}$ who indicate that in most countries greater numbers of men are diagnosed with TB than women, and men have a higher death rate from TB. Similarly, the $\mathrm{WHO}^{2}$ asserts that, globally, more men than women fall ill with TB annually, and that an estimated 5.4 million incident cases among men and 3.2 million among women were reported in 2014. Men are more likely than women to contract TB due to smoking. ${ }^{1}$

Furthermore the study revealed that a high proportion of the respondents receive less than $\mathrm{R} 1000$ per month, and are unemployed. There is a significant relationship between poverty and TB morbidity globally. According to review evidence from the World Health Organization, low-income countries are at high risk of TB. ${ }^{2}$ From the research findings, it was evident that poor people were more likely to be diagnosed with TB. Poverty has been associated with TB mortality as a strong risk factor. ${ }^{16}$ Systematic review reporting from 134 countries revealed that the incidence of tuberculosis was falling more quickly in highincome countries than in those with low income." This corresponds to a study conducted by Tshabalala, ${ }^{17}$ which concluded that poverty is a leading factor resulting in TB patients non-compliance with treatment. The majority of the respondents were residing in rural settlements $(39.1 \%)$, while $36.5 \%$ of TB patients resided in urban settlements. These findings were supported by the study of Ephrem et al., ${ }^{18}$ which shows that the 
prevalence of TB is higher in rural areas than urban areas. The study was further supported by Haider et al. ${ }^{19}$ who indicated that poor housing due to overcrowding led to increased transmission of TB, leading to weakened immunity.

Research found that destinations such as traditional healers, the church and pharmacy shops were consulted by the majority of patients before they attended healthcare facilities. A high number of diagnosed patients consulted a traditional healer before going to healthcare centres. Mathibela et al. ${ }^{20}$ further indicate that approximately $80 \%$ of people in Africa rely on traditional medicine for most of their health needs. The findings indicate that $18.92 \%$ of TB patients first visited a traditional healer, while $8.38 \%$ were using self-medication rather than seeking treatment in a clinic or hospital. The place which patients first visited contributed to the delay in reporting to a healthcare facility. The support study done by Hargreaves ${ }^{11}$ found that patients who visited traditional healers before they attended modern services had more delay in reporting to a health facility. Such types of behaviour enhance the spread of TB, and promote the risk of contracting TB among community members. The findings were supported by Viney et al., ${ }^{21}$ who found that people who have been infected by tuberculosis tend to consult a traditional healer before they seek Western medication.

Overcrowding is one of the factors that plays a major role in the transmission of tuberculosis. In this study $64.3 \%$ of families were living in single rooms, some with as many as 10 people. About $49 \%$ of the respondents had shared a single room in the past. About $23 \%$ of the respondents were living in an overcrowded household with more than three people in one single room. Similar studies in India revealed that $73.3 \%$ of TB patients lived in overcrowded residences. ${ }^{22} \mathrm{~A}$ study done in Gambia shows that TB cases increase when there is overcrowding. ${ }^{22}$ Research by Lygizos $^{23}$ found that ventilation created by opening windows and doors provide a high rate of air exchange, absolute ventilation and theoretical protection against airborne TB infection.

Stigma and societal attitudes fuel non-adherence to TB medication. The findings show that $31.8 \%$ of the respondents skipped taking medication. Tarimo ${ }^{24}$ indicates that stopping medication or skipping it results in the development of multidrug resistance. Some respondents indicated that they were ashamed when they were diagnosed with TB (20.27\%). Moreover, results show that respondents tried to hide their TB status because of stigmatisation (51.35\%). Cross-tabulation was performed to investigate geographic areas and those who hide their TB status. The findings proved statistically significant among people who live in a rural formal household, with $25(43.1 \%$; $p$-value $=0.002)$ trying to hide their status. The number of TB patients who reside in urban informal settlements associated with hiding their TB status from other community members was $76(51.35 \%$; $p$-value $=0.002)$. The findings were supported by the study done by Tarimo, ${ }^{24}$ which shows that being diagnosed with TB and fear of social isolation are obstacles to seeking timely health care.

\section{Conclusion}

This study confirms the findings of previous studies, i.e. that demographic, environmental and behavioural factors are linked to high tuberculosis morbidity in Lephalale

\section{Recommendations}

Intensive community education aimed at changing perceptions of TB risk factors, particularly ventilation and TB treatment adherence, might yield beneficial results. Community development projects aimed at empowering communities with entrepreneurial skills would also assist.

Conflict of interest - The authors hereby declare that no financial gain motivated this study.

Acknowledgement - The authors would like to thank the University of Venda for funding the study (SHS/15/PH/14/2006). The respondents are also thanked for their consent to be part of the study. The supervisors are thanked for their tireless efforts and guidance.

\section{ORCID}

\section{Thendele (iD http://orcid.org/0000-0002-0532-0244}

\section{References}

1. World Health Organization. Global tuberculosis report. 2014 Available October 2014 from: http://www/who.into/mediacenter/ factsheets/fs104/en/

2. WHO. Global tuberculosis report ISBN 9789241565059; 2015

3. Siddiqui MS, Fakih HA, Burney WA, et al. Environmental and hostrelated factors predisposing to tuberculosis in Karachi: a crosssectional study. J Pioneer Med Sci. 2011 Apr 1;1(1):13.

4. Mbengo F, Ngirande H, Ndou ND, et al. Strategies to boost the uptake of voluntary counselling and testing (VCT) by university students. Mediterr J Social Sci. 2014 Jul 4;5(15):458.

5. Pietersen E, Ignatius E, Streicher EM, et al. Long-term outcomes of patients with extensively drug-resistant tuberculosis in South Africa: a cohort study. Lancet. 2014 Apr 11;383(9924):1230. https://doi.org/10.1016/S0140-6736(13)62675-6

6. Statistics South Africa. Mortality and causes of death in South Africa, 2011: findings from death notification. Pretoria: Stats SA; 2014.

7. National Department of Health. Annual performance plan 2012/13 2014/15. National Department of Health. South Africa. Diseases. 2012;34:153-7

8. Tshitangano TG. The management of latent tuberculosis infection in health care workers at hospitals in Vhembe district. Occup Health South Afr. 2013;19(5):14-9.

9. Motsoaledi, A. South Africa's TB burden. 4th RSA TB conference. Durban. 2014.

10. Taha M, Deribew A, Tessema F, et al. Risk factors of active tuberculosis in people living with HIV/AIDS in southwest Ethiopia: a case control study. Ethiop J Health Sci. 2011 Jul;21(2):131-40.

11. Hargreaves JR, Boccia D, Evans CA, et al. The social determinants of tuberculosis: from evidence to action. Am J Public Health. 2011 Apr;101(4):654-62.

12. Padmapriyadarsini C, Narendran G, Swaminathan S. Diagnosis \& treatment of tuberculosis in HIV co-infected patients. Indian J Med Res. 2011 Dec 1;134(6):850.

13. Odone A, Houben RM, White RG, et al. The effect of diabetes and undernutrition trends on reaching 2035 global tuberculosis targets. Lancet Diabet Endocrinol. 2014 Sep 30;2(9):754-64. https://doi.org/10.1016/S2213-8587(14)70164-0

14. World Health Organization. Global tuberculosis report 2013. World Health Organization; 2013.

15. Gomes NM, Bastos MC, Marins RM, et al. Differences between risk factors associated with tuberculosis treatment abandonment and mortality. Pulm Med. 2015 Oct;27:2015.

16. Cai J, Wang X, Ma A, et al. Factors associated with patient and provider delays for tuberculosis diagnosis and treatment in Asia: a systematic review and meta-analysis. PloS One. 2015 Mar 25;10(3):e0120088. https://doi.org/10.1371/journal.pone.0120088

17. Tshabalala, DL. Tuberculosis treatment interruption; 2007.

18. Ephrem T, Mengiste B, Mesfin F, et al. Determinants of active pulmonary tuberculosis in Ambo Hospital, West Ethiopia. Afr J Prim Health Care Fam Med. 2015;7(1):1-8.

19. Haider BA, Akhtar S, Hatcher J. Daily contact with a patient and poor housing affordability as determinants of pulmonary tuberculosis in urban Pakistan. Int J of Mycobacteriology. 2013;2:38-43. 
20. Mathibela MK, Egan BA, Du Plessis HJ, et al. Socio-cultural profile of Bapedi traditional healers as indigenous knowledge custodians and conservation partners in the Blouberg area, Limpopo Province, South Africa. J Ethnobiol Ethnomed. 2015 Jun 6;11(1):1.

21. Viney KA, Johnson $P$, Tagaro $M$, et al. Tuberculosis patients' knowledge and beliefs about tuberculosis: a mixed methods study from the Pacific Island nation of Vanuatu. BMC Public Health 2014 May $17 ; 14(1): 1$

22. Hill PC, Sillah DJ, Donkor SA, et al. Risk factors for pulmonary tuberculosis: a clinic-based case control study in The Gambia. BMC Public Health 2006;6(1):156. doi:10.1186/1471-2458-6-156.
23. Lygizos M, Shenoi SV, Brooks RP, et al. Natural ventilation reduces high TB transmission risk in traditional homes in rural KwaZulu-Natal, South Africa. BMC Infect Dis. 2013 Jul 1;13(1):1.

24. Tarimo, GB. Delay in seeking care among tuberculosis patients attending tuberculosis clinics in rungwe district, Tanzania. Master of Public Health Dissertation. Muhimbili University of Health and allied Sciences; 2012. 